\title{
Differential Expression of Immune-Regulatory Protein C5AR1, NLRP3 and CLEC4A on Peripheral Blood Mononuclear Cells in Early-Stage Non-Small Cell Lung Cancer Patients
}

\section{Chirawadee Sathitruangsak}

Holistic Center for Cancer Study and Care (HOCC-PSU) Division of Medical Oncology, Department of Internal Medicine, Faculty of Medicine, Prince of Songkla University

\section{Siriporn Khunsri}

Faculty of Medicine, Chulalongkorn University

Nopporn Pornpatrananrak

Faculty of Medicine, Chulalongkorn University

Chatchawit Aporntewan

Faculty of Science, Chulalongkorn University

Poonchavist Chantranuwat

Faculty of Medicine, Chulalongkorn University

\section{Virote Sriuranpong}

Faculty of Medicine, Chulalongkorn University

\section{Apiwat Mutirangura}

Faculty of Medicine, Chulalongkorn University

Chanida Vinayanuwattikun ( $\nabla$ Chanida.Vi@chula.ac.th )

Chulalongkorn University https://orcid.org/0000-0003-3622-7752

\section{Research}

Keywords: circulating T-lymphocytes, early-stage lung cancer, protein expression, C5AR1, NLRP3, CLEC4A

Posted Date: July 22nd, 2020

DOI: https://doi.org/10.21203/rs.3.rs-44071/v1

License: (9) (1) This work is licensed under a Creative Commons Attribution 4.0 International License. Read Full License 


\section{Abstract}

Background: Previous studies from our group reported paracrine signal-induced peripheral mononuclear cell (PBMC) gene upregulation in various cancer types through epigenetic regulation. We speculated protein expression on circulating T- lymphocytes which might represent T-lymphocyte trafficking before infiltrating into tumor microenvironment. The possibility to use protein expression on circulating Tlymphocytes as a biomarker to discriminate early stage lung cancer has been explored.

Methods: PBMC gene expression was explored, using 4 independent gene expression microarray datasets (GSE12771, GSE13255, GSE20189 and GSE3934). We selected 3 candidate proteins, C5AR1, NLRP3 and CLEC4A, based on their significant protein expression in tumor-infiltrating lymphocytes but not in normal lymphoid tissue. A validation study using automated flow cytometry was conducted in 121 participants including 44 treatment-naïve early stage non-small cell lung cancer patients (NSCLC), 19 non-malignant pulmonary diseases and 62 healthy individuals.

Results: The ratio of C5AR1, NLRP3 and CLEC4A specific antibody staining to CD3 positive was significantly higher in early stage NSCLC compared to healthy control. Median ratio of C5AR1, NLRP3 and CLEC4A expression in early stage NSCLC were 0.65 [range $0.27-0.96$; $95 \% \mathrm{Cl}$ : $0.55-0.70$ ], 0.83 [range $0.27-$ $0.99 ; 95 \% \mathrm{Cl}: 0.73-0.86$ ] and 0.75 [range $0.21-0.98 ; 95 \% \mathrm{Cl}: 0.65-0.81$ ], respectively. While, median ratio of C5AR1, NLRP3 and CLEC4A expression in healthy control were 0.21 [range $0.05-0.81 ; 95 \% \mathrm{Cl}: 0.23-0.42, p$ value <0.001], 0.32 [range 0.04-0.94; 95\% Cl: 0.28-0.46, $p$-value <0.001] and 0.22 [range 0.04-0.97; $95 \% \mathrm{Cl}$ : $0.27-0.48, p$-value $<0.001]$, respectively. This led to $87.5-100 \%$ sensitivity, $50.9-64.7 \%$ specificity and $71.4-$ $75 \%$ accuracy. However, those PBMC protein expressions could not discriminate early stage NSCLC from malignant-mimic inflammation and infection.

Conclusions: Our proof-of-principle findings strengthen the hypothesis that malignancies generate distinctive protein expression fingerprints on circulating T-lymphocytes.

Trial registration: This trial was registered with clinicaltrials.in.th, Number TCTR20190508003.

\section{Background}

Lung cancer is the most common cancer and the leading cause of cancer-related death worldwide with around 2.1 million patients and an estimated 1.8 million deaths in 2018(1). The majority of lung cancer patients are diagnosed with advanced stage disease in which curative treatment is not suitable. Despite the improvement in therapy, the overall 5 -year survival rate for all stages is approximately $18 \%$ (2). Thus, there is a major effort for discovery of screening tools for early-stage disease. The National Lung Screening Trial (NLST) using low-dose helical computed tomography (LDCT) demonstrated a $20 \%$ reduction in lung cancer mortality among high-risk individuals but included a high rate of false-positive results which often leads to subsequent invasive procedures (3). 
Expression of immune-related molecules on peripheral blood mononuclear cell (PBMC) is considered to play a role in antitumor activity. The changes of gene expression profiling in PBMC seem to represent the host's response to the cancer cells via paracrine signal (4). Several studies have shown that the characterization of gene expression in PBMC may be useful as a diagnostic or for early detection (5-7). However, many technical issues limit gene expression on PBMC in investigational research. Therefore, protein expression usually correlates to mRNA expression (8). Protein expression is less complex and has a more physiologically relevant environment.

In this study, we postulate that the PBMC from early-stage non-small cell lung cancer (NSCLC) patients would have a different immune-related protein expression compared to healthy control. Discriminative expression of non-malignant pulmonary disease could enhance the potential possibility of these bloodbased biomarkers. Therefore, specific protein expression on PBMC from three separate groups of earlystage NSCLC patients, non-malignant pulmonary disease and healthy control were conducted.

\section{Materials And Methods}

\section{Candidate protein discovery}

To discover the potentially different protein expression in PBMC of early-stage NSCLC patients vs. healthy control, 4 gene expression microarray datasets provided by the Gene Expression Omnibus database (available at https://www.ncbi.nlm.nih.gov/geo/) were retrieved, including GSE12771(9), GSE13255 (5), GSE20189 (6) and GSE39345 (10). Demographic characteristic of patients from 4 gene expression datasets is shown in Table S1. Candidate up- and down-regulated gene expressions from these four independent microarray experiments were identified by using CU-DREAM (Connection Up- and DownRegulation Expression Analysis of Microarrays) (11). 1,885 significant gene expressions with $p$-values and odd ratios $>1$ which indicated strong association between the two independents studies were retrieved (Table S2). Overlapping candidate gene expressions from each gene expression microarray dataset is illustrated (Figure S1). Overlapping significant up-regulation genes of at least 3 datasets were retrieved for biological functions using the PANTHER (Protein ANalysis THrough Evolutionary Relationships) classification system (available at http://www.pantherdb.org) (12) (Figure S2). Seventyfive genes with immune system processes were identified and then mapped with pathology-based protein expression profiling in the Human Protein Atlas (available at https://www.proteinatlas.org) (13). Three significant up-regulated genes which had the presence of antibody-specific, immunohistochemistry-based protein expression on tumor-infiltrating lymphocytes (TILs) in tumor specimen but not in normal lymphoid tissue were selected, including CLEC4A, C5AR1, NLRP3 (Figure S3). Details of selected gene ontology in homo sapiens based on the PANTHER are summarized in Table S3.

\section{Study Population}


Forty-four patients with early-stage non-small cell lung cancer (NSCLC), 20 patients with non-malignant pulmonary disease and 57 healthy volunteers who received treatment at The King Chulalongkorn Memorial Hospital, Bangkok, Thailand were recruited in a prospective manner. Inclusion criterion were $\geq 18$ year-old with either resectable NSCLC staging system based on pathologic result of the seventh edition of the American Joint Committee on Cancer (AJCC) Cancer Staging System (14) or non-malignant pulmonary disease were enrolled. Healthy volunteers must have had no history of malignant disease with normal chest radiography within 6 months before or after enrollment. The exclusion criterion were prior systemic therapies, including cytotoxic chemotherapy, small molecule targeted therapy, immunotherapy, history of another malignancy within 5 years before enrollment and receipt of corticosteroids or any immunosuppressive agents. All study participants gave written informed consent. Demographic characteristics were obtained from individual patients. This study was approved by the Ethics Committee of the Faculty of Medicine, Chulalongkorn University, Bangkok, Thailand (IRB 211/61).

\section{Blood Collection and Preparation}

Whole blood samples were collected in EDTA containers from all participants. Peripheral mononuclear cell (PBMC) were isolated using Ficoll-Paque ${ }^{\mathrm{TM}}$ PLUS (GE Healthcare Life Sciences, Canada) as previously described (15). Briefly, blood samples were centrifuged at $1600 \times \mathrm{g}$ at $16{ }^{\circ} \mathrm{C}$ for 10 minutes. After removal plasma, the specimen was diluted (1:1) with phosphate buffered saline (PBS) solution. Then, gently layering the diluted plasma on top of the Ficoll in a new conical tube and centrifuged at $2000 \mathrm{rpm}$ for 30 minutes. The interface between plasma and Ficoll layer was collected and then washed twice with $10 \mathrm{ml}$ of PBS solution. Specimens were kept in 5\% DMSO mixed with culture media at $-196{ }^{\circ} \mathrm{C}$ until further analyzed.

\section{Immunofluorescence and set up condition}

Formalin-fixed paraffin-embedded tissue samples were cut into five micrometers using a rotary microtome. Here, we used human spleen (anti-C5AR1 antibody), stomach (anti-CLEC4A antibody) and tonsil (anti-NLRP3) as positive control. For antigen retrieval step, slides were boiled in $10 \mathrm{mM}$ sodium citrate buffer ( $\mathrm{pH}$ 8.0) at $95^{\circ} \mathrm{C}$ for 20 minutes Model: PT-Link, Dako. After incubation time, slides were cooled down on bench-top for 30 minutes and washed with distilled water for 5 minutes. Primary antibody was diluted with 1\% Fetal Bovine Serum (FBS) in PBS at a 1:200 dilutions and dropped on each sample slide. Sample slides were incubated overnight at $4{ }^{\circ} \mathrm{C}$ and washed three times with PBS for 10 minutes. Secondary antibody (Anti-Rabbit IgG Fab2 Alexa Fluor® 488 Molecular Probes) was diluted with $1 \%$ FBS in PBS at a 1:200 dilution, dropped on the slides and incubated at $4{ }^{\circ} \mathrm{C}$ for 1 hour in dark place. After incubation, slides were washed three times with PBS. Anti-CD45 antibody (MEM-28) (\#AB8216, Abcam) was diluted with $1 \%$ FBS in PBS at a 1:500 dilutions, dropped on the slides and incubated at $4{ }^{\circ} \mathrm{C}$ overnight. Slides were washed and incubated with Goat Anti-Mouse IgG H\&L (Alexa Fluor® 647) preabsorbed (\#AB150119, Abcam) at 1:500 dilutions for 1 hour at 4॰C in a dark place. Hoechst 33342 
(\#4082, Cell Signaling Technology) at the concentration of $1 \mu \mathrm{g} / \mathrm{ml}$ was dropped on the slides. Slides were incubated at $4{ }^{\circ} \mathrm{C}$ for 15 minutes in a dark place and washed slides three times with PBS for 10 minutes. Slides were tapped off on tissue paper to eliminate the excess water, then one drop of PRoLong ${ }^{\circledR}$ Gold Antifade Reagent (\#9071, Cell Signaling Technology) was added and covered with glass coverslips, all edges of slides were coated with clear fingernail polisher to prevent cells from drying. Slides were examined under a fluorescent microscope (Figure S4).

\section{Flow cytometry analysis}

To shorten the time-consuming process, we adapted the protocol of protein expression assessment to automated flow cytometry. A monoclonal antibody to the CD3 antigen was used to identify target lymphocyte populations. PBMCs were seeded in 96 -well V-bottom plate at $2 \times 10^{6}$ cells per well. The plate was centrifuged at $500 \mathrm{~g}$ for 5 minutes at $4{ }^{\circ} \mathrm{C}$ and was washed with $50 \mu \mathrm{l}$ of cold PBS. Three primary antibodies were used in this study including C5AR1 (Cat. No. HPA014520, Sigma), CLEC4A (Cat. No. HPA007842, Sigma), NLRP3 (Cat. No. HPA012878, Sigma). These primary antibodies were diluted at 1:500 with $3 \%$ FBS in PBS, added to the well, and incubated for 1 hour at $4 \circ \mathrm{C}$. After incubation, cells were washed three times with $50 \mu \mathrm{l}$ cold PBS. Cells were incubated with secondary antibody Anti-Rabbit lgG Fab2 Alexa Fluor® 488 Molecular Probes (Cat. No. 4412S, Cell Signaling Technology) using 1:200 dilutions for 30 minutes at $4 \circ \mathrm{C}$ in dark place. Cells were washed and incubated with the conjugated primary antibody APC anti-mouse CD3 antibody (Cat. No. 100312, BioLegend) at 1:200 dilutions for 30 minutes at $4 \circ \mathrm{C}$ in a dark place. Cells were washed and resuspended in PBS. At least 10,000 focus cells for each sample were collected and analyzed using FlowSight Imaging Flow Cytometry (Amnis, USA). INSPIRE (MilliporeSigma) integrated software was used for data collection. Image analysis was performed with ImageStream Data Exploration and Analysis Software (IDEAS software version 6.2.64.0, MilliporeSigma) following IDEAS User's Manual guide (Figure S5).

\section{Statistical Analysis}

Statistical parameters considered for characterization protein expression on the PBMC is as follows; 1 ) ratio of specific-antibody positive to CD3 positive, 2) average fluorescence intensity of specific-antibody staining with CD3 positive 3) average adjusted fluorescence intensity calculated by average fluorescence intensity $\times$ ratio of specific-antibody positive to CD3 positive. Mann-Whitney $U$ test was used to assess differences among non-parametric continuous ratios and intensity of fluorescence staining positive between groups. Receiver operative characteristic (ROC) curve analysis was used to analyze sensitivity and specificity of particular gene expressions as a potential diagnostic marker for early-stage NSCLC. The two-sided test $p$-values $<0.01$ were considered significant. All the statistical analyses were performed with the use of R program, version 3.6.3.

\section{Results}




\section{Demographic characteristics of study participants}

We enrolled at total of 121 study participants, 44 treatment-naïve early-stage NSCLC patients, 20 nonmalignant pulmonary diseases and 57 healthy individuals. The median age of early-stage NSCLC patients was 63.5 years [range 34-83]. Seventy-two percent of patients were female. All patient had ECOG performance of $0-1$. A majority $(97.7 \%)$ of histology was adenocarcinoma. Pathological stage I disease accounted for $68.2 \%$. All patients received curative attempt operation such as lobectomy and bilobectomy. The median age for the non-malignant pulmonary diseases and healthy controls were 48.5 years [range 30-76] and 58 years [range 30-86], respectively. Ninety-five percent of non-malignant pulmonary disease patients presented with pulmonary nodule mimic lung cancer and had operative procedure. A majority (75\%) of resected lung tissue histology was infection and inflammation. Details of patient demographics and disease characteristics at study enrollment are provided in Table 1. 
Table 1

Baseline clinical characteristics of early-stage NSCLC patients, non-malignant pulmonary diseases and healthy control participants.

\begin{tabular}{|c|c|c|c|}
\hline Characteristics & $\begin{array}{l}\text { Early NSCLC } \\
\text { patients } \\
(n=44)(\%)\end{array}$ & $\begin{array}{l}\text { Non-malignant } \\
\text { pulmonary disease (n } \\
=20)(\%)\end{array}$ & $\begin{array}{l}\text { Healthy } \\
\text { Controls } \\
(n=57)(\%)\end{array}$ \\
\hline \multicolumn{4}{|l|}{ Age } \\
\hline$\geq 60$ year & $30(68)$ & $7(35)$ & $27(47.3)$ \\
\hline$<60$ year & $14(32)$ & $13(65)$ & $30(52.7)$ \\
\hline \multicolumn{4}{|l|}{ Sex, n (\%) } \\
\hline Male & $12(27.3)$ & $8(40)$ & $20(36)$ \\
\hline Female & $32(72.7)$ & $12(60)$ & $37(64)$ \\
\hline \multicolumn{4}{|l|}{ Smoking, $\mathrm{n}(\%)$} \\
\hline Current & $5(11.3)$ & $5(25)$ & $2(3.5)$ \\
\hline Former & $7(15.9)$ & $7(35)$ & $3(5.2)$ \\
\hline Never & $32(72.8)$ & $8(40)$ & $52(91.3)$ \\
\hline \multicolumn{4}{|l|}{ Histology; malignancy, n (\%) } \\
\hline Adenocarcinoma & $43(97.7)$ & $\mathrm{N} / \mathrm{A}$ & N/A \\
\hline Adenosquamous cell carcinoma & $1(2.3)$ & & \\
\hline \multicolumn{4}{|l|}{ Histology; non-malignancy, n (\%) } \\
\hline Granulomatous inflammation & $\mathrm{N} / \mathrm{A}$ & $12(60)$ & N/A \\
\hline Nodular amyloidosis & & $2(10)$ & \\
\hline $\begin{array}{l}\text { Bronchiectasis with chronic } \\
\text { inflammation }\end{array}$ & & $1(5)$ & \\
\hline Chronis & & $3(15)$ & \\
\hline . & & $1(5)$ & \\
\hline Hyalinized fibrous nodule & & $1(5)$ & \\
\hline Necrotizing lymphoid hyperplasia & & & \\
\hline
\end{tabular}




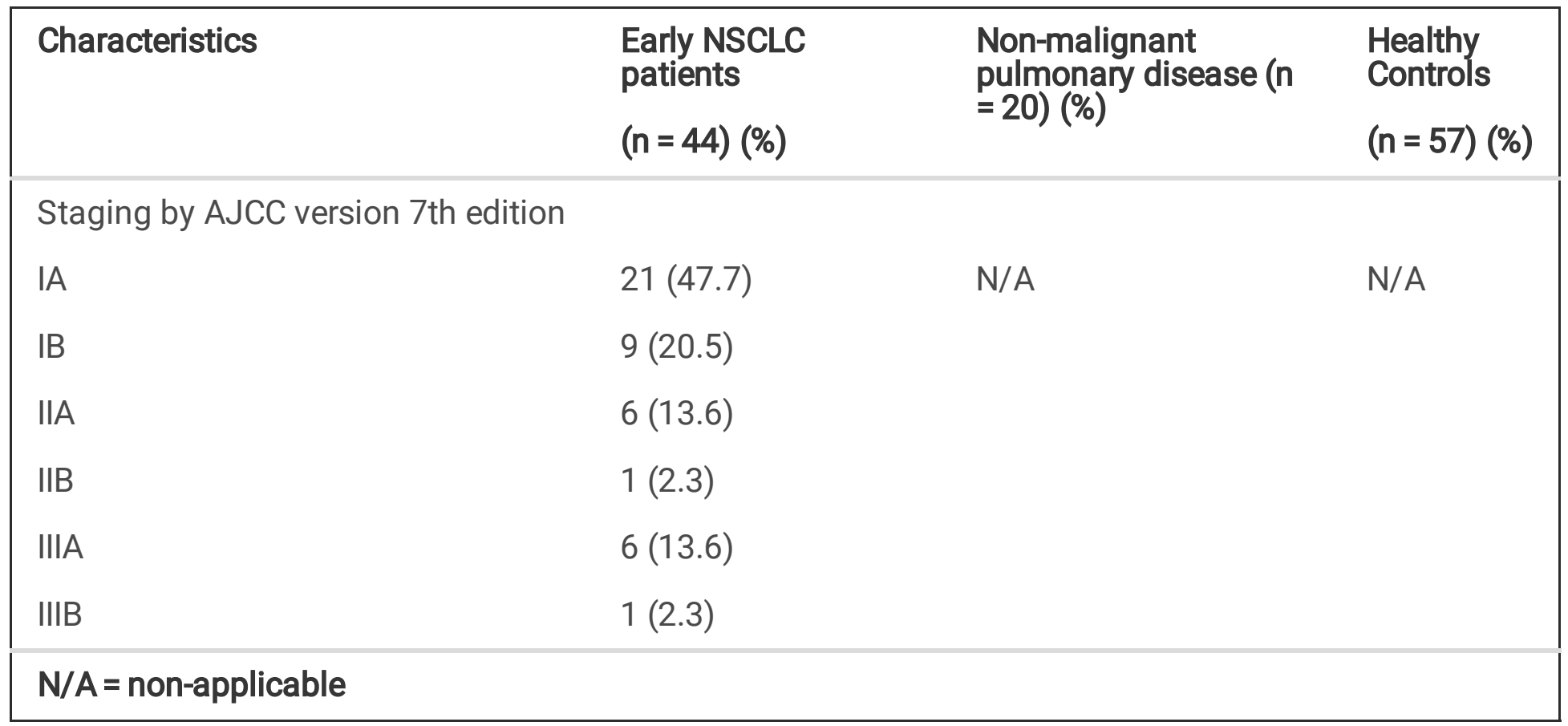

\section{Quality control assessment and storage time effect}

Specific CD3 positive lymphocyte was our population of interest. Automated CD3 positive expression flow cytometry could detect over 10,000 PBMC of 3 protein expression assays: C5AR1, NLRP3 and CLEC4A in $86.7 \%, 83.4 \%$ and $85.1 \%$, respectively. Median collected freezing time of PBMC to automated flow cytometry testing was 19.6 months [range 0-100.4 month; $95 \% \mathrm{Cl} 15.9-40$ ]. There was no difference in freezing time of PBMC for both over and under 10,000 PBMC detection of C5AR1, NLRP3 and CLEC4A protein expression (Mann-Whitney $\mathrm{U}$ test; $p$-value $0.5,0.8$ and 0.8 , respectively). Long-term storage in $-196{ }^{\circ} \mathrm{C}$ did not affect the quality of protein detection.

\section{Protein expression on PBMC in early-stage lung cancer patients and healthy controls}

The potential of protein expression as a biomarker for early lung cancer detection was first explored comparing to healthy control. The ratio of specific antibody staining to CD3 positive was calculated from the number of specific antibody staining to CD3 positive. Median ratio of C5AR1, NLRP3 and CLEC4A expression in early-stage NSCLC patients were 0.65 [range $0.27-0.96 ; 95 \% \mathrm{Cl}: 0.55-0.70$ ], 0.83 [range $0.27-0.99 ; 95 \% \mathrm{Cl}: 0.73-0.86$ ] and 0.75 [range $0.21-0.98 ; 95 \% \mathrm{Cl}: 0.65-0.81$ ], respectively. While, median ratio of C5AR1, NLRP3 and CLEC4A expression in healthy controls were 0.21 [range $0.05-0.81 ; 95 \% \mathrm{Cl}$ : $0.23-0.42$, $p$-value < 0.001 ], 0.32 [range $0.04-0.94 ; 95 \% \mathrm{Cl}: 0.28-0.46, p$-value $<0.001$ ] and 0.22 [range $0.04-0.97 ; 95 \% \mathrm{Cl}: 0.27-0.48, p$-value $<0.001]$, respectively. The number of those CD3 positive cells with specific antibody expressions were higher in early-stage NSCLC patients than healthy controls. 
In addition to the number of positive staining, flow cytometry also enables the determining of the fluorescence intensity on the cell surface of each specific antibody-stained cell. The average intensity of C5AR1, NLRP3 and CLEC4A expressions in early-stage NSCLC patients were 528.6 [range 342.9-1065.6; 95\% Cl: 472-554.4], 622.1 [range 440.7-1227; 95\% Cl: 605-730.7] and 614.2 [range 350.8-1128.3; 95\% Cl: 575.9-695.3], respectively. While, average intensity of C5AR1, NLRP3 and CLEC4A expression in healthy controls were 619.6 [range 305.8-2465.8; $95 \% \mathrm{Cl}$ : 575.1-725, $p$-value 0.002], 535.1[range 311.2-1852.7; 95\% Cl: 520.6-616.5, $p$-value 0.008] and 532.1 [range 356.3-1364.8; 95\% Cl: 528.7-631.9, $p$-value 0.14], respectively. The average adjusted specific protein expression was calculated from average intensity expression $\times$ ratio of specific antibody staining to CD3 positive. Average adjusted expression of C5AR1, NLRP3 and CLEC4A in early-stage NSCLC patients were 317.8 [range 104.2-1023.8; 95\% Cl: 273.5-386.4], 536.1 [range 171.8-1217; 95\% Cl: 464.1-604.1] and 466.7 [range 135.9-928.4; $95 \% \mathrm{Cl}$; $410.5-530.2$ ]. The average adjusted expression of C5AR1, NLRP3 and CLEC4A in healthy controls were 140.8 [range 33.22002.7; 95\% Cl: 141.3-303.1, p-value 0.004], 190 [range 12.7-1754; 95\% Cl: 147.5-299.1, p-value < 0.001] and 133.8 [range 15.3-1325.7; 95\% Cl: 138-312.4, $p$-value < 0.001] (Table 2). Both ratio and average adjusted intensity of C5AR1, NLRP3 and CLEC4A were significant higher in early-stage NSCLC patients compared to healthy controls. This suggests that the number of specific protein expression of C5AR1, NLRP3 and CLEC4A on immune cell surface changes in the presence of cancer. The comparison of ratio and average adjusted fluorescence intensities of specific protein expression on CD3 positive lymphocytes between early NSCLC patients and healthy controls are shown in Fig. 1. 
Table 2

Shows results of C5aR1, NLRP3 and CLEC4A protein expression of circulating T- lymphocyte of 121 study participants including 44 early-stage NSCLC patients, 20 non-malignant pulmonary diseases and 57 healthy controls.

\begin{tabular}{|c|c|c|c|c|}
\hline & Total $(n=121)$ & $\begin{array}{l}\text { Early-stage } \\
\text { NSCLC }(n=44)\end{array}$ & $\begin{array}{l}\text { Non-malignant } \\
\text { pulmonary } \\
\text { disease }(n=20)\end{array}$ & $\begin{array}{l}\text { Healthy } \\
\text { control }(n= \\
57)\end{array}$ \\
\hline \multicolumn{5}{|l|}{ C5aR1 expression } \\
\hline - Pass QC ${ }^{*}$ & $86.7 \%$ & $86.3 \%$ & $89.4 \%$ & $85.9 \%$ \\
\hline - Ratio\# [range] & $0.50[0.05-0.99]$ & $0.65[0.27-0.96]$ & $0.75[0.34-0.99]$ & $0.21[0.05-$ \\
\hline $\begin{array}{l}\text { - Average expression } \\
\text { [range] }\end{array}$ & $\begin{array}{l}565.9[305.8- \\
2465.8]\end{array}$ & $\begin{array}{l}528.6[342.9- \\
1065.6]\end{array}$ & $\begin{array}{l}538.6[370.9- \\
1177.4]\end{array}$ & $619.6[305.8-$ \\
\hline $\begin{array}{l}\text { - Adjusted expression } \\
\text { [range] }\end{array}$ & $\begin{array}{l}271[33.2- \\
2002.7]\end{array}$ & $\begin{array}{l}317.8[104.2- \\
1023.8]\end{array}$ & $\begin{array}{l}348.3[190.3- \\
1172.4]\end{array}$ & $\begin{array}{l}\text { 140.8 [33.2- } \\
2002.7]\end{array}$ \\
\hline \multicolumn{5}{|l|}{ NLRP3 expression } \\
\hline - Pass QC & $83.4 \%$ & $90.9 \%$ & $70 \%$ & $82.4 \%$ \\
\hline - Ratio [range] & $0.68[0.04-0.99]$ & $0.83[0.27-0.99]$ & $0.87[0.32-0.99]$ & $0.32[0.04-$ \\
\hline $\begin{array}{l}\text { - Average expression } \\
\text { [range] }\end{array}$ & $\begin{array}{l}587.8[311.2- \\
1852.7]\end{array}$ & $\begin{array}{l}622.1[440.7- \\
1227]\end{array}$ & $\begin{array}{l}627.1[464.4- \\
1091.9]\end{array}$ & $\begin{array}{l}535.1[311.2- \\
1852.71\end{array}$ \\
\hline $\begin{array}{l}\text { - Adjusted expression } \\
\text { [range] }\end{array}$ & $\begin{array}{l}400.6[12.7- \\
1754]\end{array}$ & $\begin{array}{l}536.1[171.8- \\
1217]\end{array}$ & $\begin{array}{l}532.7[201.2- \\
797.1]\end{array}$ & $\begin{array}{l}190[12.7- \\
1754]\end{array}$ \\
\hline \multicolumn{5}{|l|}{ CLEC4A expression } \\
\hline - Pass QC & $85.1 \%$ & $88.6 \%$ & $75 \%$ & $85.9 \%$ \\
\hline - Ratio [range] & $0.67[0.04-0.99]$ & $0.75[0.21-0.98]$ & $0.80[0.19-0.99]$ & $0.22[0.04-$ \\
\hline $\begin{array}{l}\text { - Average expression } \\
\text { [range] }\end{array}$ & $\begin{array}{l}578.9[350.8- \\
1364.8]\end{array}$ & $\begin{array}{l}614.2[350.8- \\
1128.3]\end{array}$ & $\begin{array}{l}631.8[396.3- \\
919.1]\end{array}$ & 532.1 [356.3- \\
\hline $\begin{array}{l}\text { - Adjusted expression } \\
\text { [range] }\end{array}$ & $\begin{array}{l}379.6[[15.3- \\
1325.7]\end{array}$ & $\begin{array}{l}466.7[135.9- \\
928.4]\end{array}$ & 499 [77-918.5] & $\begin{array}{l}133.8[15.3- \\
1325.7]\end{array}$ \\
\hline \multicolumn{5}{|c|}{$\begin{array}{l}\text { *Pass QC accounting percentage of specimen that had more than } 10,000 \mathrm{CD} 3+\text { in each specific } \\
\text { antibody }\end{array}$} \\
\hline
\end{tabular}

\section{Protein expression on PBMC as potential candidate to discriminate early-stage non-small cell lung cancer patients}




\section{from healthy controls}

To assess the potential to discriminate early-stage NSCLC patients from healthy controls, optimal cut-off ratio of each specific antibody staining positive with CD3 positive was conducted. The C5AR1 expression ratio cut-off value at 0.28 could distinguish early-stage NSCLC patients from healthy controls at $100 \%$ sensitivity and $50.9 \%$ specificity ( 0.77 area under the ROC curve, accuracy rate $71.4 \%$ ). The NLRP3 expression ratio cut-off value at 0.58 could distinguish early-stage NSCLC patients from healthy controls at $87.5 \%$ sensitivity and $64.7 \%$ specificity ( 0.83 area under the ROC curve, accuracy rate $74 \%$ ). The CLEC4A expression ratio cut-off value at 0.34 could distinguish early-stage NSCLC patients from healthy controls at $97.4 \%$ sensitivity and $57.1 \%$ specificity ( 0.80 area under the ROC curve, accuracy rate $75 \%$ ) (Fig. 1). Specific protein expression ratio to CD3 positive staining showed better discrimination power than average adjusted protein expression.

\section{Protein expression on PBMC in early-stage lung cancer and non-malignant pulmonary disease}

An important clinical issue in the discovery of a biomarker is the ability to discriminate non-malignant pulmonary nodules. We explored specific antibody expression staining to CD3 positive in 20 nonmalignant pulmonary diseases compared to early-stage NSCLC patients. C5AR1, NLRP3 and CLEC4A expression ratios in non-malignant pulmonary disease were 0.75 [range $0.34-0.99 ; 95 \% \mathrm{Cl}: 0.60-0.71, p$ value 0.2 ], 0.87 [range $0.32-0.99 ; 95 \% \mathrm{Cl}: 0.66-0.92$, $p$-value 0.62 ] and 0.80 [range $0.19-0.99 ; 95 \% \mathrm{Cl}$ : $0.63-0.87, p$-value 0.57 , respectively. Average intensity of C5AR1, NLRP3 and CLEC4A expression in nonmalignant pulmonary disease were 538.6 [range 370.9-1177.4; 95\% Cl: 471.4-604.9, $p$-value 0.48], 627.1 [range 464.4-1091.9; 95\% Cl: 556.8-778.1, $p$-value 0.92] and 631.8 [range 396.3-919.1; 95\% Cl: 528.5$696.3, p$-value 0.69], respectively. Neither ratio nor intensity expression specific antibody staining in CD3 positive revealed a difference to early-stage NSCLC patients. Immune cell reaction of C5AR1, NLRP3 and CLEC4A could not discriminate non-malignant process to malignant process.

\section{Discussion}

Previous studies from our group reported paracrine signal-induced PBMC gene upregulation in various cancer types through epigenetic regulation $(4,16,17)$. On the basis of paracrine signal-induced PBMC gene upregulation, we explored the possibility to use protein expression on circulating T-lymphocytes as a biomarker to discriminate early-stage NSCLC and healthy individuals by automated flow cytometry analysis. We speculated that protein expression on circulating T- lymphocytes might represent Tlymphocyte trafficking before infiltrating into tumor microenvironment. In the first-stage in this report, we chose proteins which related to immune function in either innate and/or adaptive immune processes. We found that ratios of all 3 chosen markers; C5AR1, CLEC4A, NLRP3 protein expression had been significantly increased in early-stage NSCLC patients compared to healthy controls. The discriminative sensitivity ranged $87.5-100 \%$ and specificity ranged $50.9-64.7 \%$. Thus, measuring these proteins may 
allow us to distinguish early-stage NSCLC patients from healthy controls. Our proof-of-principle findings strengthen the hypothesis that malignancies generate distinctive protein expression fingerprints on circulating T-lymphocytes.

In more detail of the 3 chosen markers, CLEC4A (C-type lectin domain family 4 member a) or dendritic immunoreceptor (DCIR) has been reported as an immune suppressor of dendritic cells which play a crucial role in the adaptive immune response. CLEC4A expresses on various immune cells depending on stage of maturation (18). Current evidence shows a role of CLEC4A down-regulation via small hairpin RNA inhibited tumor progression in animal models (19). NLRP3 (NOD-, LRR- and pyrin domain-containing 3 ) inflammasome complex plays a role in the innate immune signaling. Aberrant NLRP3 involves in various inflammatory conditions, infection immune responses and including cancer control (20). C5AR1 (complement component 5 a receptor 1 ) is a $\mathrm{G}$ protein-coupled receptor for $\mathrm{C} 5 \mathrm{a}$. It functions as a complement receptor and modulates inflammatory responses via chemokine and cytokine signaling pathway. C5AR1 signaling contributes to the promotion of tumor growth by suppressing the adaptive immune response against tumor antigens and recruits myeloid-derived suppressor cells (MDSCs) into tumor (21). Considering function and mechanistic-relation of these 3 protein expressions, it might be the reason why we could not use them to discriminate non-malignant pulmonary disease with a majority of inflammation and infection from early-stage non-small cell lung cancer.

The technique measures fluorescence signals through a laser source. Gating techniques allows the simultaneously measurement of the cell surface protein expression on a single cell level (22). The detection of a specific antigen by flow cytometry is a rapid, easy and a semi-quantitative assay. Therefore, flow cytometry with immunofluorescence-labeled cells is a promising tool for the profiling of cell surface protein signaling from peripheral blood samples in clinical practice. It may provide valuable information for assessment and cancer monitoring during treatment. Further elucidation in cancerspecific PBMC protein expression might provide information for lung cancer screening.

\section{Conclusions}

Our proof-of-principle findings strengthen the hypothesis that malignancies generate distinctive protein expression fingerprints on circulating T-lymphocytes.

\section{List Of Abbreviations}

AJCC, American Joint Committee on Cancer; C5AR1, complement component 5a receptor 1; CD, Cluster of differentiation; CLEC4A, C-type lectin domain family 4 member A; CU-DREAM, Connection Up- and DownRegulation Expression Analysis of Microarrays; FITC, fluorescein isothiocyanate; MDSCs, myeloid-derived suppressor cells; NSCLC, non-small cell lung cancer; PANTHER, Protein ANalysis THrough Evolutionary Relationships classification system; TILs, tumor-infiltrating lymphocytes

\section{Declarations}




\section{Ethics approval and consent to participate}

All assessments were approved by the Medical Ethics Committee of the Faculty of Medicine, Chulalongkorn University, Bangkok, Thailand (IRB 211/61). All experimental methods were carried out in accordance with the approved guidelines and regulations. Fully written informed consent was obtained from all participants.

\section{Consent for publication}

Not applicable.

\section{Availability of data and materials}

All data generated or analyzed during this study are included in this published article.

\section{Competing interests}

The authors declare that they have no competing interests.

\section{Funding}

This research was supported by the Ratchadapiseksompotch Fund, Faculty of Medicine, Chulalongkorn University (Grant number RA61/089) to CV, Chulalongkorn Academic Advancement into Its 2nd Century (CUAASC) Project to VS and CV and National Science and Technology Development Agency (Grant number FDA-CO-2561-8477-TH) to AM.

\section{Authors contributions}

CS; Patient enrollment, Data curation Writing- original draft. SK; Methodology, Investigation. PC; Methodology, Investigation, Writing-review and editing. VS; Writing-review and editing, Funding acquisition. CV; Patient enrollment, Data curation, Methodology, Investigation, Funding acquisition, Writing-original draft, Writing-review and editing. AM; Conceptualization, Funding acquisition, Writingreview and editing. All authors read and approved the final manuscript.

\section{Acknowledgments.}

The authors would like to thank the nursing staff of the Medical Oncology Unit for completing blood sample collection from non-small cell lung patients and Ms. Chatcha Phromma for her technical 


\section{References}

1. Bray F, Ferlay J, Soerjomataram I, Siegel RL, Torre LA, Jemal A. Global cancer statistics 2018 : GLOBOCAN estimates of incidence and mortality worldwide for 36 cancers in 185 countries. Ca-a Cancer Journal for Clinicians. 2018;68(6):394-424.

2. Siegel RL, Miller KD, Jemal A. Cancer Statistics, 2018. Ca-a Cancer Journal for Clinicians. 2018;68(1):7-30.

3. National Lung Screening Trial Research T, Aberle DR, Adams AM, Berg CD, Black WC, Clapp JD, et al. Reduced lung-cancer mortality with low-dose computed tomographic screening. N Engl J Med. 2011;365(5):395-409.

4. Boonsongserm $P$, Angsuwatcharakon $P$, Puttipanyalears $C$, Aporntewan $C$, Kongruttanachok $N$, Aksornkitti V, et al. Tumor-induced DNA methylation in the white blood cells of patients with colorectal cancer. Oncol Lett. 2019;18(3):3039-48.

5. Showe MK, Vachani A, Kossenkov AV, Yousef M, Nichols C, Nikonova EV, et al. Gene Expression Profiles in Peripheral Blood Mononuclear Cells Can Distinguish Patients with Non-Small Cell Lung Cancer from Patients with Nonmalignant Lung Disease. Cancer Research. 2009;69(24):9202-10.

6. Rotunno M, Hu N, Su H, Wang CY, Goldstein AM, Bergen AW, et al. A Gene Expression Signature from Peripheral Whole Blood for Stage I Lung Adenocarcinoma. Cancer Prevention Research. 2011;4(10):1599-608.

7. Zander T, Hofmann A, Staratschek-Jox A, Classen S, Debey-Pascher S, Maisel D, et al. Blood-Based Gene Expression Signatures in Non-Small Cell Lung Cancer. Clinical Cancer Research. 2011;17(10):3360-7.

8. Edfors F, Danielsson F, Hallstrom BM, Kall L, Lundberg E, Ponten F, et al. Gene-specific correlation of RNA and protein levels in human cells and tissues. Molecular Systems Biology. 2016;12(10).

9. Zander T, Hofmann A, Staratschek-Jox A, Classen S, Debey-Pascher S, Maisel D, et al. Blood-based gene expression signatures in non-small cell lung cancer. Clin Cancer Res. 2011;17(10):3360-7.

10. Chen YC, Hsiao CC, Chen KD, Hung YC, Wu CY, Lie CH, et al. Peripheral Immune Cell Gene Expression Changes in Advanced Non-Small Cell Lung Cancer Patients Treated with First Line Combination Chemotherapy. Plos One. 2013;8(2).

11. Aporntewan C, Mutirangura A. Connection up- and down-regulation expression analysis of microarrays (CU-DREAM): a physiogenomic discovery tool. Asian Biomedicine. 2011;5(2):257-62.

12. Mi H, Dong Q, Muruganujan A, Gaudet P, Lewis S, Thomas PD. PANTHER version 7: improved phylogenetic trees, orthologs and collaboration with the Gene Ontology Consortium. Nucleic Acids Res. 2010;38(Database issue):D204-10.

13. Uhlen M, Bjorling E, Agaton C, Szigyarto CA, Amini B, Andersen E, et al. A human protein atlas for normal and cancer tissues based on antibody proteomics. Molecular \& Cellular Proteomics. 
2005;4(12):1920-32.

14. AJCC Cancer Staging Manual. 8 ed. Chicago: Springer International Publishing; 2017.

15. Kleiveland C. Peripheral blood mononuclear cells. In: Verhoeckx K, Cotter P, López-Expósito I, Kleiveland C, Lea T, Mackie A, et al., editors. The impact of food bioactives on health in vitro and ex vivo models. Cham: Springer; 2015. p. 161-7.

16. Arayataweegool A, Srisuttee R, Mahattanasakul P, Tangjaturonsasme N, Kerekhanjanarong V, Kitkumthorn $\mathrm{N}$, et al. Head and neck squamous cell carcinoma drives long interspersed element-1 hypomethylation in the peripheral blood mononuclear cells. Oral Dis. 2019;25(1):64-72.

17. Puttipanyalears $C$, Kitkumthorn N, Buranapraditkun S, Keelawat S, Mutirangura A. Breast cancer upregulating genes in stromal cells by LINE-1 hypermethylation and micrometastatic detection. Epigenomics. 2016;8(4):475-86.

18. Bates EE, Fournier N, Garcia E, Valladeau J, Durand I, Pin JJ, et al. APCs express DCIR, a novel C-type lectin surface receptor containing an immunoreceptor tyrosine-based inhibitory motif. J Immunol. 1999;163(4):1973-83.

19. Weng TY, Li CJ, Li CY, Hung YH, Yen MC, Chang YW, et al. Skin Delivery of Clec4a Small Hairpin RNA Elicited an Effective Antitumor Response by Enhancing CD8(+) Immunity In Vivo. Mol Ther Nucleic Acids. 2017;9:419-27.

20. Mangan MSJ, Olhava EJ, Roush WR, Seidel HM, Glick GD, Latz E. Targeting the NLRP3 inflammasome in inflammatory diseases. Nat Rev Drug Discov. 2018;17(8):588-606.

21. Markiewski MM, DeAngelis RA, Benencia F, Ricklin-Lichtsteiner SK, Koutoulaki A, Gerard C, et al. Modulation of the antitumor immune response by complement. Nature Immunology. 2008;9(11):1225-35.

22. Moskalensky AE, Chernyshev AV, Yurkin MA, Nekrasov VM, Polshchitsin AA, Parks DR, et al. Dynamic quantification of antigen molecules with flow cytometry. Journal of Immunological Methods. 2015;418:66-74.

\section{Figures}


Ratio expression to CD3
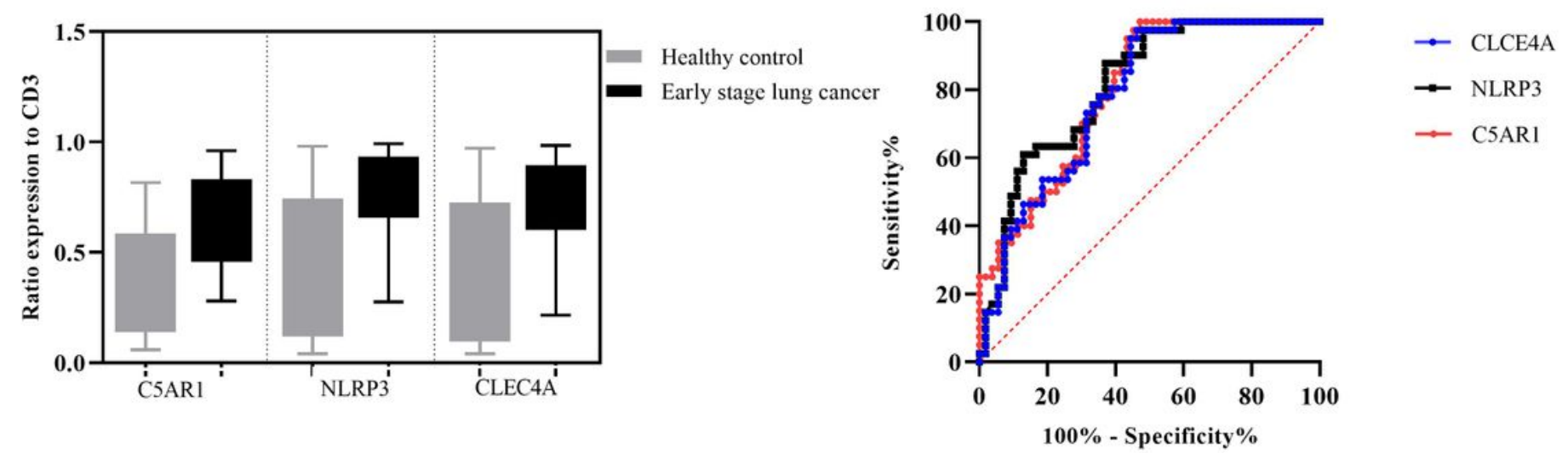

Adjusted expression
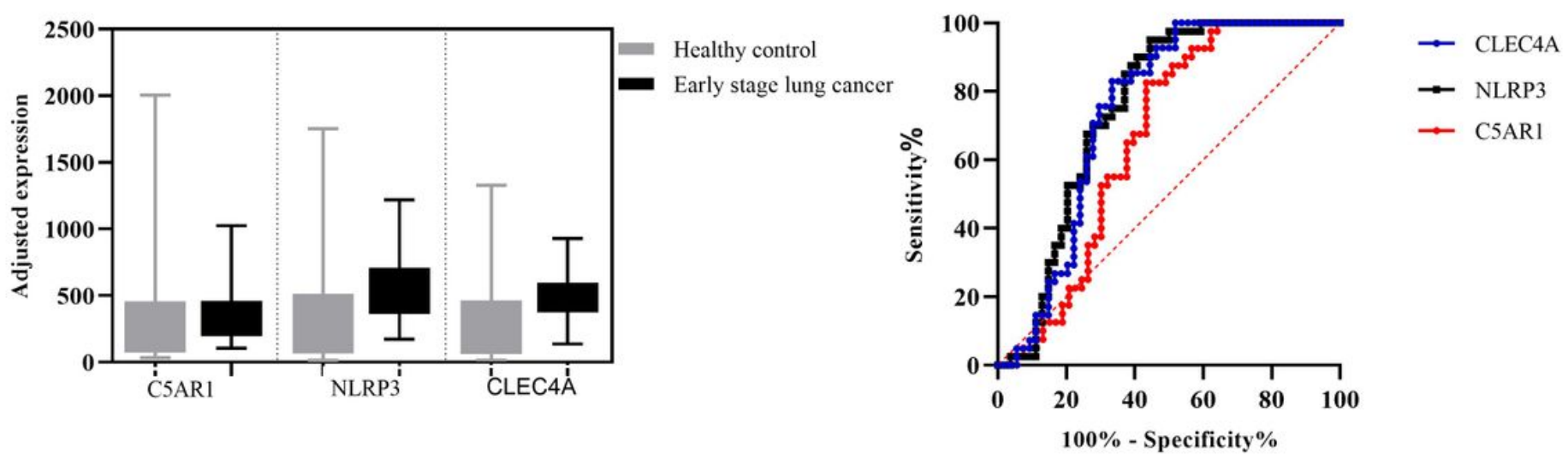

Figure 1

Represents ratio expression of C5AR1, NLRP3 and CLEC4A between healthy control and early-stage NSCLC patient and area under the curve (above). Cut-off value at $0.28,0.58$ and 0.34 for C5AR1, NLRP3 and CLEC4A ratio expression could represent $87.5-100 \%$ sensitivity and $50-64.7 \%$ specificity. Average adjusted expression (calculated by average intensity $\times$ ratio expression) of C5AR1, NLRP3 and CLEC4A between healthy control and early-stage NSCLC patient and area under the curve are also represented (below). 


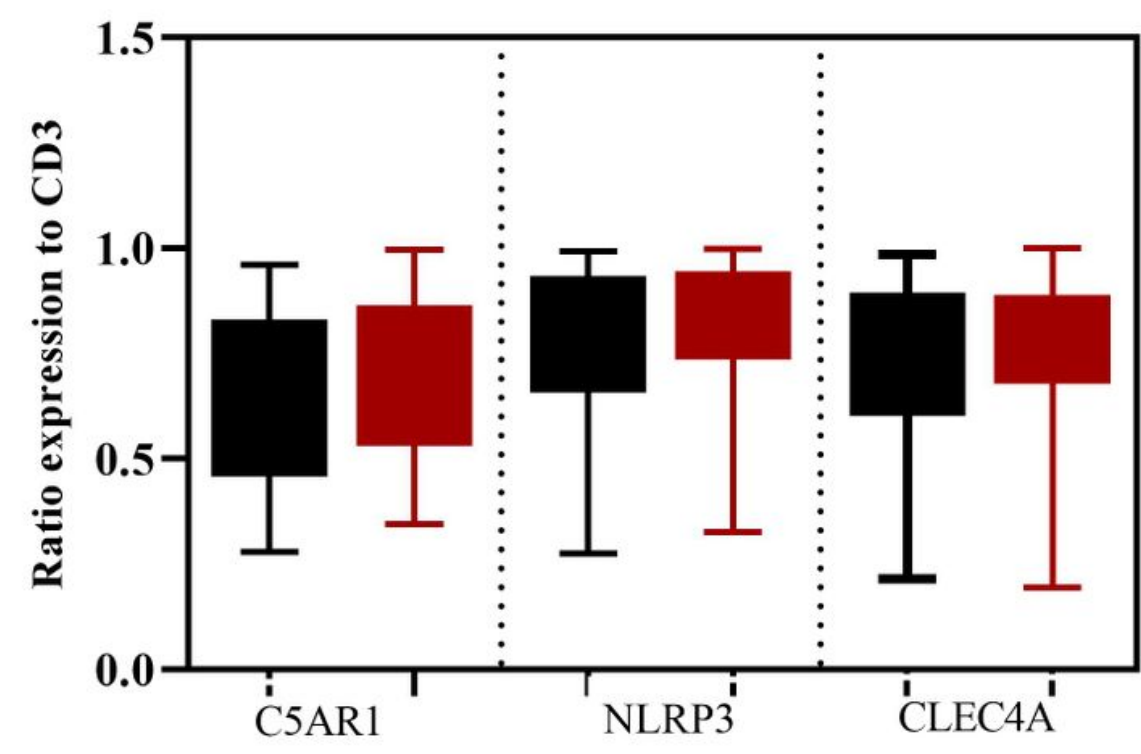

- Early stage lung cancer

Non-malignant pulmonary disease

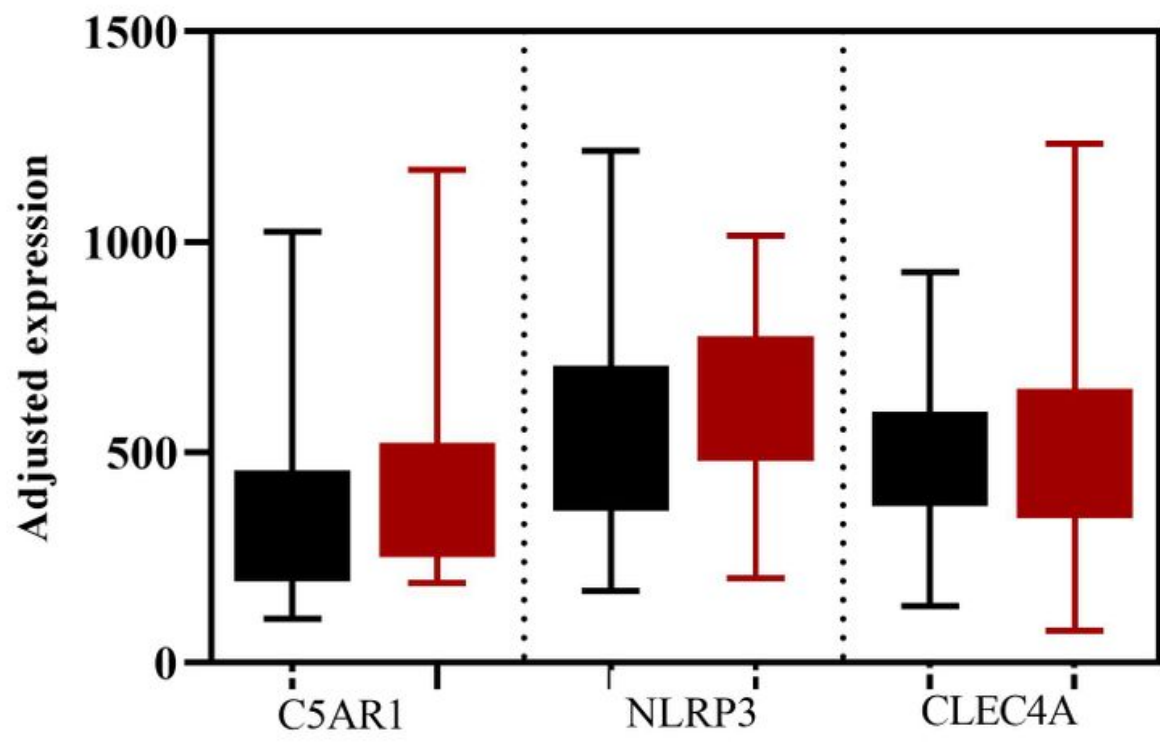

Early stage lung cancer Non-malignant pulmonary disease

Figure 2

Represents similarity of both ratio expression (above) and adjusted expression (below) of C5AR1, NLRP3 and CLEC4A in non-malignant pulmonary diseases and early-stage NSCLC patients.

\section{Supplementary Files}

This is a list of supplementary files associated with this preprint. Click to download.

- PBMCSignaturesuppTable270620.xlsx 
- PBMCSignaturesuppFig270620.docx 